\title{
Top Management Involvement in Open Innovation Processes: Learning from a Global Carmaker
}

\author{
Elena Candelo $^{1}$, Diego Matricano ${ }^{2}$, Mario Sorrentino ${ }^{2}$ \\ ${ }^{1}$ Department of Management, University of Turin, Corso Unione Sovietica, 218/bis - 10134 Torino, Italy \\ ${ }^{2}$ Department of Management, Università degli Studi della Campania "Luigi Vanvitelli”, Corso Gran Priorato di \\ Malta - 81043 Capua (CE), Italy \\ Correspondence: Diego Matricano, Department of Management, Università degli Studi della Campania "Luigi \\ Vanvitelli”, Corso Gran Priorato di Malta - 81043 Capua (CE), Italy.
}

Received: May 18, 2018

doi:10.5539/ibr.v11n7p142
Accepted: June 18, 2018

Online Published: June 26, 2018

URL: https://doi.org/10.5539/ibr.v11n7p142

\begin{abstract}
Over the last decades, management scholars have largely investigated several aspects related to Open Innovation Processes - OIPs that concern the beginning, the diffusion and the future developments of the phenomenon, its typologies, its linkages with strategies and business models, its implementation, and even errors to be avoided when managing them. However, there is one aspect that seems to be underexplored and this deals with the involvement of top management.

OIPs, like all the other managerial activities, need to be planned and defined ex ante; implemented, launched and managed; analyzed ex post. Thus, a decisional process - pertaining the activities to be carried out, human resources to be involved, criticalities to be avoided and results to be exploited - needs to be managed. Accordingly, the research question posed herein is: How do top managers handle OIPs?

In order to respond to the above research question, a case study is presented hereinafter. This case study deals with an OIP launched by Fiat Chrysler Automobiles (FCA), one of the top ten global carmakers, and concerning the car of the future. In particular, through this case study, it is rebuilt and analysed how FCA top managers have handled the whole OIP.

By leveraging on the achieved results, the paper speculates on the strong commitment that top managers need to put in practice if they aspire to make OIPs successful.
\end{abstract}

Keywords: open innovation, top management involvement, decisional process, automotive industry, carmakers

\section{Introduction}

Undoubted relevance achieved by open innovation - OI (Chesbrough, 2003, 2004) has driven management scholars to investigate the phenomenon in reference to several aspects. Some of them have investigated OI related aspects that vary from the foundations of the phenomenon (Enkel et al., 2009; Loren, 2011) to its probable evolutions (Gassman et al., 2010; Chesbrough, 2012) passing through its dissemination (Chesbrough \& Crowther, 2006). Other scholars, instead, have investigated the typologies of OI (Phillips, 2011); still other scholars have focused their attention on the impact that OI can have according to already implemented strategies (Chesbrough \& Appleyard, 2007) and already adopted business models (Frankenberger et al., 2014). Scholars' attention has also been paid on the errors that might invalidate expected results (Gaule, 2011), on the role of feedback related to idea generation (Wooten \& Ulrich, 2017) and on the start-of-the-art of OI culture (Matricano, 2018). However, from a dedicated literature review, it results that one of the underexplored topics deals with involvement of top management.

Very often, in reference to innovation, the role of top management has been questioned. Even if some scholars argue that top management contribution to innovation is limited because of the nature of their jobs (according to Hambrick et al. (2005) it is a top level involvement that does not support innovation in a straight way), other scholars - actually most of them - have underlined their positive impact on building innovation capabilities (Felekoglu \& Moultrie, 2014; Wang \& Dass, 2017).

However, in reference to OIPs, management scholars have not investigated this topic of research. Part of this 
missing might be due to the fact that when talking about OIPs attention moves towards the involvement of the external stakeholders (such as suppliers, universities, experts) and of crowd - that plays a crucial role - rather than towards the involvement of top management. Actually, top managers need to plan and define ex ante all the activities to be carried out in order to realize a crowd based OIP. They are involved in implementing, launching and managing OIPs; eventually, they are expected to analyze achieved results ex post. According to the above, it seems that involvement of top management in OIPs cannot be underestimated.

By leveraging on a single case study, related to a pilot OIP managed by one of the top ten global carmakers, Fiat Chrysler Automobiles (FCA), the present paper aims to investigate and conceptualize the relevance of top management involvement in OIPs. Accordingly, the paper is structured as follows. In the next subsections, the paper reviews OI specialist literature referred to the involvement of top management in reference to innovation generally meant and rebuilds the state-of-the-art of OI in the automotive industry. In section two, the methodology adopted for the research (single case study) is presented and in section three the OIP case study launched by FCA is rebuilt and results are presented. In the last section, after highlighting the limitations of the study, the relevance of the involved of top management in OIPs is discussed and the main conclusions of the paper are drawn.

\subsection{The Role of Top Managers in Building Innovation Capability}

Despite some scepticism about to role of top managers in innovation processes (Hambrick et al., 2005) mainly due to the nature of their jobs (it is a top level involvement that does not support innovation in a straight way), management scholars largely agree on the relevance that top management has in reference to innovation and above all - to building innovation capability (Felekoglu \& Moultrie, 2014; Wang \& Dass, 2017). As rebuilt by Wang and Dass (2017), the role of top management in reference to innovation and innovation capabilities can be studied according to managers' profiles (age, tenure, experience, social culture), to composition of top management teams, and to the involvement of top managers in innovation processes. In reference to the involvement of top managers, Wang and Dass (2017, p. 127), who recall Smith and Tushman's contribution (2005), underline the importance of "managers' direct roles in promoting firms' innovation capabilities". Put simply, the above scholars maintain that top managers are required to facilitate innovativeness by investing in innovation-related activities. A controversial issue deals with the definition of innovation-related activities. In the past (Hegarty \& Hoffman, 1990), in fact, innovation-related activities were referred to specific projects that, time by time, were planned and managed. Nowadays, instead, innovation-related activities are meant at company level (O'Cass \& Sok, 2013; Rosing et al., 2011; Wang \& Dass, 2017). This means that top managers - who are strategic decision-makers - are expected to address all the activities towards innovation. In other words, top managers are expected "to systematically build capabilities for innovation" (Börjesson et al., 2014, p. 120).

Even if management scholars largely support what was said above in reference to innovation processes taking place inside firms, it seems that up to now there has been a scarce interest in the role that top managers play in OIPs. Over these processes, in fact, firms are expected to combine internal and external ideas, knowledge, capabilities and intangible resources in order to carry out innovation-related activities (Chesbrough, 2003). Accordingly, it happens that intellectual property, ideas, and people can move outside in and inside out of firms (Chesbrough \& Garman, 2009; Matricano, 2017). Top managers, then, are expected to manage a greater amount of innovation-related activities since they need to combine internal and external aspects. For this reason, it seems appropriate to investigate the role of top managers in OIPs. Since innovation-related activities are industry specific, hereinafter attention is paid only on the automotive industry. In this industry, in fact, over the last decades there has been an increasing number of OIPs that has allowed exploring several innovations (Di Minin et al., 2010; Enkel \& Gassman, 2010; Ili et al., 2010; Cabigiosu et al., 2013; Karlsson \& Sköld, 2013; Lazzarotti et al., 2013). Despite this, generalized results and specific insights still need to be unfolded (Ili et al., 2010). Involvement of top managers is among these.

\subsection{Open Innovation in the Automotive Industry}

According to Rubenstein (2014), introduction of radical innovations in the automotive industry is not easy for several reasons. For a start, automotive industry requires considerable capital investments. It is known that companies try to achieve economies of scale in the production of vehicles in order to reduce (or even minimize) unit costs. Moreover, rigorous security controls and environmental directives rule automotive industry. In addition, the core products - i.e. cars - have not undergone deep changes over last decades (the oil-based engines are still the same). Eventually, as for the demand, customers are not so inclined to pay a premium price for innovations.

The above analysis shows that fostering continuous innovation in the automotive industry is a complex task for 
large-scale carmakers. Traditionally, automotive industry has leveraged on internal R\&D for its business strategies (Miller, 1994; Peters \& Becker, 1997; Aggeri et al., 2009; MacNeill \& Bailey, 2010). In recent years, instead, carmakers are increasing their level of openness in fostering innovation activities (Di Minin et al., 2010; Enkel \& Gassman, 2010; Ili et al., 2010; Cabigiosu et al., 2013; Karlsson \& Sköld, 2013; Lazzarotti et al., 2013; Cano-Kollmann et al., 2018). Thus it seems that OI is becoming an emerging valuable top-down strategy in the automotive industry (Ili et al., 2010).

From an extensive literature review, it results that several cases can be cited in this vein. PSA Group invited the crowd to redefine the aesthetic characteristics of cars (Bughin et al., 2008) and asked experts and customers for new ideas concerning technology, car consuming and autonomous vehicles (www.openinnovation.net). Logan (2011) investigated the OIPs launched by Tesla Motors and aiming to predict electric vehicles for the automotive industry. Enkel and Gassman (2010) analyzed and compared three OIPs launched in the automotive industry. BMW launched the first one analyzed by the scholars. Over this OIP, partners from the entertainment industry were asked to develop a new device able to controlling some functions within BMW cars. As for the Wittenstein case (the second one), the OIP involved several experts in order to use a new technology to stretch human bones. The Sevex/Elringklinger case is the third and last one analyzed by Enkel and Gassman (ibidem). The OIP concerned heat shields. Di Minin et al. (2010) analyzed an OIP launched by FCA aiming to modify some characteristics of the engines defined by the Fiat Research Centre (CRF) together with external engineers and technicians. Brondoni (2010), Estellés-Arolas and González-Ladrón-De-Guevara (2012) and Saldanha et al. (2014) reviewed and rebuilt the MIO case, an OIP managed by FCA Brazil. Eventually, King and Lakhani (2013) presented the case of Local Motors while Lazzarotti et al. (2013) rebuilt the case of Pininfarina, focused on design, engineering, and manufacturing aspects, and the case of Bosch concerning products, functions, services, processes and business models.

The above literature review discloses that most of the studies about OI in the automotive industry are focused on the ideas and insights expected by the crowd or on the kind of crowd that is involved. In reference to the former, scholars underlined the interest for autonomous vehicles (Bughin et al., 2008), electric vehicles (Logan, 2011), characteristics of the engines (Di Minin et al., 2010), and futuristic design (Lazzarotti et al., 2013). In reference to the latter, scholars emphasized the involvement of industrial/research partners (Enkel \& Gassman, 2010; Di Minin et al., 2010; Logan, 2011; Lazzarotti et al., 2013), designers (De Massis et al., 2012; King \& Lakhani, 2013; Lazzarotti et al., 2013), of suppliers (Karlsson \& Sköld, 2013; Lazzarotti et al., 2013; Wilhelm \& Dolfsma, 2018) or of the crowd as a whole. Particularly, "Fiat MIO" case involved over 17,000 participants (Saldanha et al., 2014). However, in presenting their cases, the above-cited scholars did not focus on the involvement of top managers in OIPs.

To the best knowledge of the authors, involvement of top managers has only been investigated in reference to internal innovation processes (Börjesson et al., 2014) but not in reference to OIPs. Accordingly, the research question posed herein is: How do top managers handle OIPs?

\section{Method}

The authors had the opportunity to act as external advisors over the implementation of the OIP launched by FCA. Accordingly, FCA top managers responsible of the OIP were willing to provide detailed information through direct interviews. Because of this great opportunity, this OIP was selected as single case study at the basis of this research (Eisenhardt, 1989; Yin, 1994).

From a methodological perspective, it is appropriate to recall two different points of view about the methodology of case study. On the one hand, some management scholars do question the generalization of results that can be achieved through case study and so they do not embrace the idea that generalized results can be achieved (Dyer \& Wilkins, 1991; Eisenhardt \& Graebner, 2007). On the other hand, other scholars argue that a single case study can be used to propose and support theoretical advancements (Eisenhardt, 1989; Dyer \& Wilkins, 1991; Yin, 1994). These advancements can take place if the topic of research is characterized by high level of newness and thus previous theoretical or empirical contributions related to it are missing (Glase \& Strauss, 1967). Since there are no previous studies focused on the role of top management in OIPs in the automotive industry, it seems that the methodology of a single case study can be appropriate for this research.

In order to rebuild FCA case study, direct interviews with FCA top managers were carried out. In particular, top managers involved in strategic planning, product planning, engineering, $\mathrm{R} \& \mathrm{D}$, and marketing activities were interviewed. The above direct interviews aimed at investigating the basic research issue, that is, how FCA top managers have handled the OIPs. Of course, even if dedicated questions to be asked were prepared according to the role and functions of the interviewed managers, asked questions varied according to the dynamics of interviews. 


\section{Results of the Case Study}

Before launching the pilot OIP, four direct interviews were conducted with FCA top managers involved in the OIP (May-June 2015). Thus, following Huber and Power (1985), knowledgeable informants who were supposed to be able to provide the most relevant information were selected. In particular, top managers involved in strategic planning, product planning, engineering, $\mathrm{R} \& \mathrm{D}$, and marketing activities were interviewed. The authors, acting as external advisors, asked open questions aiming to understand the current innovation strategy of FCA, its level of openness and its previous open innovation activities. After the interviews, there was a close interaction between the authors and FCA top management over the whole OIP (2015-2016). The project ended with an in-depth interview with the Head of Product Planning and Institutional Relations of EMEA Region. This interview took place after the conclusion of the pilot OIP. By and large, the result of the interviews was that FCA top managers aspired to start and manage a pilot OIP that could really collect new insights and ideas about the car of the future.

During the meetings hold to define the main aspects of the OIP, FCA top managers decided to start from the potential customers and to ask them about their needs and about their view of the car of the future. In this vein, FCA top managers identified the target, its characteristics and size. As for the characteristics, FCA top managers were informed that if the target is numerous and assorted, then the risk of addressing wrong innovative paths increases. However, if the target is standardized and limited, then members of the target can think and act in a similar way and so results might be not significant and robust enough (Hopkins, 2011; Phillips, 2011). As for size of target, FCA top managers were also informed that approximately one per cent of involved crowd joins OIPs (Hopkins, 2011). Therefore, it is important to refer to a big sample in order to get a significant amount of answers.

After appropriate evaluations, FCA top managers decided to involve and in particular young millennials aged between 18 and 24 (Prensky, 2001). According to AutoTrader (2013) and KPMG (2015), this target can be considered as key customers in the automotive industry since they allow foreseeing future trends in the automotive industry. They are expected to be future car buyers/users and, above all, they are expected to choose their cars according to their needs and their preferences.

In particular, FCA top management decided to investigate the point of view of young millennials attending management classes. The main reason was that these students are not expected to have advanced technical or engineering competences so they can express their idea of the car without any constraint. Only young millennials studying management in two Italian universities (University of Campania "L. Vanvitelli" and University of Cassino and Lazio Meridionale) were invited to join the pilot OIP.

As already said, FCA top managers wanted young millennials to communicate their needs and the technology or distinctive competencies they preferred. As for questions to be asked, FCA top managers were informed that there are two alternatives to evaluate (Phillips, 2011). If companies already know what they seeking, then they can solicit dedicated questions (direct). On the contrary, if companies do not know what they are seeking, then they can solicit generic questions (suggestive). In this last case, provided answers can disclose unpredicted paths of research. FCA top managers decided to ask four direct questions:

1) How do you foresee cars in 15 years?

2) What would you do with your car if you could?

3) What do you expect by carmakers to improve your life?

4) How can music, social nets and friends improve your relationship with your car?

At this stage, FCA top management had to define other issues related to invitation (or call) and incentives. As for invitation, Phillips (2011) suggests four types of invitation: suggestive/participative, suggestive/invitational, direct/invitational or directed/participative. In case of suggestive/participative call, everyone can suggest broad ideas; in case of suggestive/invitational call, exclusive subjects are invited to suggest broad ideas; in case of direct/invitational call, exclusive subjects are invited to suggest dedicated ideas; eventually, in case of directed/participative call, everyone can propose dedicated ideas.

FCA top managers decided that the pilot OIP was invitational and questions were suggestive (in this way the risk that members of the target could think in a similar way was significantly reduced). In order to make the invitation as efficient as possible, FCA top managers decided to leverage an intermediary that, by definition (Enkel et al., 2009; Sieg et al., 2010; Frey et al., 2011; Zogaj et al., 2014), facilitates the match between companies and the crowd. In particular, FCA decided to leverage on Start up Lab, an academic laboratory of the Department of Management of University of Campania "L. Vanvitelli" focused on entrepreneurship and open 
innovation. In particular, Start up Lab managed all the activities concerning the promotion of the OIP and the creation of a dedicated digital platform (Chesbrough, 2012; Rayna \& Striukova, 2015). This was done since it is well known that Internet technologies can reduce search costs and maximize information flows (Whelan et al., 2010).

In order to steer the crowd to join OIPs, incentives are necessary (Hopkins, 2011). FCA top managers decide to offer an internship (lasting over 6-months) in a FCA plant to each of the four winners. At this stage, the pilot OIP was launched. It was October 2015.

After FCA top managers defined all the above critical issues, some junior projects managers - under the direct supervision of FCA top managers - organized promotion activities in order to invite young millennials to post their ideas. It was estimated that students joining the promotion activities were nearly 1,200. During these promotion activities, students were informed they had to respond to the above cited questions available on a dedicated web page linked to the website of the Start up Lab.

The collection of answers started on October and ended by December 2015. During these three months, the junior projects managers organized some events useful to recall the pilot OIP. After the deadline, the junior projects managers involved in the projects found out that 501 millennials provided valid answers. For sure, it is a higher than expected percentage (Hopkins, 2011).

Two senior project managers carried out the content analysis of provided answers. Before proceeding, it is appropriate to remind that millennials could provide open answers. This implies that they could share several ideas (more then only one) and - above all - that the full amount of ideas and insights can go beyond the number of participants (501 millennials).

As for responses to the first question "How do you foresee cars in 15 years?" 501 millennials provided 762 ideas/insights. $46.0 \%$ of respondents expect that cars in the future will be green. By this, millennials mean water-fuelled cars, boosted by electric motors, equipped with solar panels or with internal accessories made up of renewable/recycled materials. $25.4 \%$ of respondents expect that cars in the future will be smart. These cars are should include "outside-in sensors", concerning speed, proximity, temperature, and "inside-out sensors", related to health or emotions. $7.7 \%$ of respondents expect that cars in the future will be safe. Lower percentages of respondents (respectively $5.6 \%$ and $5.0 \%$ ) expect that cars in the future will be comfortable (able to identify drivers but - at the same time - able to go driverless and groundbreaking in terms of design.

As for responses to the second question "What would you do with your cars if you could?" 501 young millennials provided 616 ideas/insights. $43.1 \%$ of respondents would like to have all their stuff accessible when they travel since this is their main hobby/interest. $21.9 \%$ of young millennials would like to drive smartly by having their car equipped with outside-in (speed, proximity, and temperature) and inside-out sensors (health-related, emotional). 9.7\% of young millennials would like to increase their personal leisure and thus they would like a car able to remember the places (through pictures made by cars themselves) and to share them with friends (through social networks implemented in their cars). Finally, young millennials would like to drive in a very comfortable way (7.2\%), thus their cars should be driverless or with a driver assistant, and to get superior performances (5.9\%) in terms of speed, safety and fuel consumption.

As for responses to the third question "What do you expect by carmakers to improve your life?" 501 young millennials provided 626 ideas. Answers to this question confirm that young millennials really ask for green (25.8\%), safe (22.5\%), smart (19.8\%), and comfortable (6.1\%) cars in the future. However, if possible, young millennials would also like low-cost cars (6.4\%). This answer supports the idea that customers are not so inclined to pay a premium price for innovations (Rubenstein, 2014). Carmakers, then, are expected to balance the above insights (green, safe, smart and comfortable) with an affordable price.

As for responses to the fourth question, namely "How can music, social nets \& friends improve your relationship with your car?", 501 young millennials provided 552 ideas. According to $22.8 \%$ of respondents, social networks are part of millennials' life but they want to feel safe when they use them. In reference to this, many young millennials support the idea that voice-activated commands could be effective. Young millennials also maintain that cars of the future should be the result of technological convergence (14.2\%). Put simply, cars of the future should support all the devices (smart-phones, tablets, or laptops), should be able to get info about and share info with their friends' in order to be always on (14.2\%). The idea of belonging to a dedicated network created by FCA $(13.6 \%)$ and the idea that cars could be considered personal assistant $(9.3 \%)$ are really attractive for young millennials.

In addition to the content analysis of provided answers, the Innovation Board (made up of FCA top managers 
and academics) selected the best ideas and insights in terms of originality, feasibility and sustainability.

These best ideas were under deeper evaluation by both the FCA product planning team and CRF top managers. FCA engineers working them had the opportunity to meet the young millennials proposing these best ideas and to discuss the ideas with them. Of course, as expected, several difficulties rose over the meetings because of different ages, education, backgrounds, languages and expectations between FCA engineers and millennials. However, the fact that FCA top managers wanted and planned these meetings was a powerful driver for engineers who - in turn - were really committed in making them happen and - above all - in maximizing the exchanges of innovative ideas and insights.

At this stage, any comment about the exploitation of the achieved results in terms of ideas, insights and devices is not possible because of the non-disclosure agreement signed with FCA. However, even if it is not possible to know if and how FCA top managers have used the achieved results, for sure FCA top managers have evaluated the pilot OIP in a positive way. Up to now (2018), in fact, FCA has launched two additional extended editions of the OIP directed to the same target but living and studying in six regions in the South of Italy. The new editions of the OIP have been entitled "I AM FCA" - an acronym standing for "Innovation Award Millennials FCA". Implicitly this means that FCA top managers have largely appreciated the results achieved through the pilot OIP.

\section{Discussion and Conclusions}

From a managerial perspective, the FCA case study presented above has some implications that need to be carefully discussed.

Involvement in the FCA experience has shown that involvement of top managers in defining and managing the OIP can definitively be seen as a key-aspect for achieved success. FCA top managers, in fact, have shown strong involvement and commitment since the very beginning of the project (when the aim of the OIP was defined by FCA top managers). Beyond that, FCA top managers have identified the most critical issues (concerning the target, the questions, invitation and incentives). They have supervised the events planned by the junior projects managers in order to promote the OIP. They have been directly involved in the selection of the best ideas and in the organization of the meeting between engineers and millennials. In reference to this, initial difficulties and obstacles were overcome since FCA top managers had strongly recommended internal engineers to maximize the achievable results or, in other words, to catch the insights and ideas proposed by millennials. Even if top managers have not evaluated themselves and their involvement in the OIP, perceived success is confirmed by the fact that two new extended editions of the OIP have been launched.

At this stage, before deriving some implications for management scholars and - above all - for managers interested in launching OIPs, some limitations need to be discussed. The first limitation is methodological and concerns the use of a single case study while the second is industry-related and concerns the generalization of results.

In reference to the first limitation, it is well known that the choice of using qualitative methods based on a single case study might prevent the generalization of achieved results and the proposal of a general theory or model (Dyer \& Wilkins, 1991; Eisenhardt \& Graebner, 2007). Of course, this is also true for this paper. However, this choice is appropriate when the topic of research is groundbreaking and copious empirical data or theoretical contributions are not available (Eisenhardt, 1989; Yin, 1994). This is the case for this paper since it aims to investigate the role of top management in OIPs in the automotive industry. Moreover, the choice of a single case study seemed to be appropriate if we consider the possibility of investigating an OIP promoted by one of top 10 global carmakers.

In reference to the second limitation, it is appropriate to recall again the characteristics of the automotive industry (Rubenstein, 2014). As already said, introduction of significant innovations in the automotive industry is not easy because of considerable capital investments, achievement of economies of scale, rigorous security controls and environmental directives, the characteristics of core products, and the customers' scarce inclination to pay premium price for innovations. The above characteristics of the automotive industry (which seem to slow down the speed of innovation) might have required a different involvement of top managers in comparison to other industries. Accordingly, results achieved in this paper cannot be easily generalized and referred to other industries that follow different innovation paths - see for example (Laursen \& Salter, 2006; Chiaroni et al., 2010).

At this stage, it is possible to move forward and discuss some implications for management researchers and for managers interested in launching OIPs. Management scholars should seek other companies that have implemented OIPs in order to confirm the relevance of top managers' involvement. By analyzing and comparing 
the involvement of top managers in OIPs, then it is possible to assess if and to what extent top managers are expected to plan and define ex ante, implement, launch and manage and then analyze ex post innovation-related activities. New insights about company-related and industry-related aspects might come out. The above-cited paths represent interesting alternatives that might add something to the present work.

As for managers interested in launching OIPs, the FCA case study discloses that the risk of addressing wrong paths or unsatisfying results seems to be minimized if top managers are directly involved over the whole OIP and if they can properly manage knowledge boundaries (Wilhelm \& Dolfsma, 2018). Top managers, who are strategic decision-makers, are expected "to systematically build capabilities for innovation" (Börjesson et al., 2014). FCA experience shows that this can be achieved only if they supervise all the OIP (from its definition to the analysis of achieved results). At a wider level, the FCA case study shows and confirms the importance of top-down strategies in promoting OI in the automotive industry (Ili et al., 2010; Cano-Kollmann et al., 2018). In fact, the decision to promote the OIP has been taken by the Coo of EMEA Region who serves also as Head of FCA Business Development and who personally projected and checked all the aspects of the initiative.

In conclusion, it seems reasonable to argue that top managers' involvement works as a powerful role model and has a positive impact on the definition and implementation of innovation-related activities over OIPs.

\section{Acknowledgement}

Although this article is the result of a joint effort of analysis and reflection, EC authored subsection 1.2, sections 2 and 4, DM authored subsection 1.1 and section 3 and MS authored section 1. All the authors read and approved the final manuscript.

\section{References}

Aggeri, F., Elmquist, M., \& Pohl, H. (2009). Managing learning in the automotive industry - the innovation race for electric vehicles. International Journal of Automotive Technology and Management, 9(2), 123-147. https://doi.org/10.1504/IJATM.2009.026394

AutoTrader (2013). The Next Generation Car Buyers. Millennials. Report retrieved from www.autotrader.com.

Börjesson, S., Elmquist, M., \& Hooge, S. (2014). The challenges of innovation capability building: Learning from longitudinal studies of innovation efforts at Renault and Volvo Cars. Journal of Engineering and Technology Management, 31, 120-140. https://doi.org/10.1016/j.jengtecman.2013.11.005

Brondoni, S. M. (2010). Intangibles, Global Networks \& Corporate Social Responsibility. Symphonia, 2, 6-24.

Bughin, J., Chui, M., \& Johnson, B. (2008). The next step in open innovation. McKinsey Quarterly, 4, 1-8.

Cabigiosu, A., Zirpoli, F., \& Camuffo, A. (2013). Modularity, interfaces definition and the integration of external sources of innovation in the automotive industry. Research Policy, 42(3), 662-675. https://doi.org/10.1016/j.respol.2012.09.002

Cano-Kollmann, M., Awate, S., Hannigan, T. J., \& Mudambi, R. (2018). Burying the Hatchet for Catch-Up: Open Innovation among Industry Laggards in the Automotive Industry. California Management Review, $60(2), 17-42$.

Chesbrough, H. (2003). Open Innovation: The New Imperative for Creating and Profiting from Technology. Boston (MA): Harvard Business School Press.

Chesbrough, H. (2004). Managing open innovation. Research-Technology Management, 47(1), 23-26. https://doi.org/10.1080/08956308.2004.11671604

Chesbrough, H. (2012). Open innovation: Where we've been and where we're going. Research-Technology Management, 55(4), 20-27. https://doi.org/10.5437/08956308X5504085

Chesbrough, H. W., \& Garman, A. R. (2009). How open innovation can help you cope in lean times. Harvard Business Review, 87(12), 68-76.

Chesbrough, H., \& Appleyard, M. (2007). Open innovation and strategy. California Management Review, 50(1), 57-76. https://doi.org/10.2307/41166416

Chesbrough, H., \& Crowther, A. K. (2006). Beyond high tech: early adopters of open innovation in other industries. $R \& D$ Management, 36(3), 229-236. https://doi.org/10.1111/j.1467-9310.2006.00428.x

Chiaroni, D., Chiesa, V., \& Frattini, F. (2010). Unravelling the process from Closed to Open Innovation: evidence from mature, asset-intensive industries. $R \& D$ Management, 40(3), 222-245. https://doi.org/10.1111/j.1467-9310.2010.00589.x 
De Massis, A., Lazzarotti, V., Pizzurno, E., \& Salzillo, E. (2012). Open innovation in the automotive industry: a multiple case study. Management of Technological Innovation in Developing and Developed Countries, March, 217-236.

Di Minin, A., Frattini, F., \& Piccaluga, A. (2010). Fiat: open innovation in a downturn (1993-2003). California Management Review, 52(3), 132-159. https://doi.org/10.1525/cmr.2010.52.3.132

Dyer, W. G., \& Wilkins, A. L. (1991). Better Stories, Not Better Constructs, to Generate Better Theory: A Rejoinder to Eisenhardt. Academy of Management Review, 16(3), 613-619. https://doi.org/10.5465/amr.1991.4279492

Eisenhardt, K. M. (1989). Building Theories from Case Study Research. Academy of Management Review, 14(4), 532-550. https://doi.org/10.5465/amr.1989.4308385

Eisenhardt, K. M., \& Graebner, M. E. (2007). Theory building from cases: Opportunities and challenges. The Academy of Management Journal, 50(1), 25-32. https://doi.org/10.5465/amj.2007.24160888

Enkel, E., \& Gassman, O. (2010). Creative imitation: exploring the case of cross-industry innovation. $R \& D$ Management, 40(3), 256-270. https://doi.org/10.1111/j.1467-9310.2010.00591.x

Enkel, E., Gassmann, O., \& Chesbrough, H. (2009). Open R\&D and open innovation: exploring the phenomenon. $R \& D$ Management, 39(4), 311-316. https://doi.org/10.1111/j.1467-9310.2009.00570.x

Estellés-Arolas, E., \& González-Ladrón-De-Guevara, F. (2012). Towards an integrated crowdsourcing definition. Journal of Information Science, 38(2), 189-200. https://doi.org/10.1177/0165551512437638

Felekoglu, B., \& Moultrie, J. (2014). Top management involvement in new product development: A review and synthesis. Journal of Product Innovation Management, 31(1), 159-175.

Frankenberger, K., Weiblen, T., \& Gassman, O. (2014). The antecedents of open business models: an exploratory study of incumbent firms. R\&D Management, 44(2), 173-188. https://doi.org/10.1111/radm.12040

Frey, K., Lüthje, C., \& Haag, S. (2011). Whom should firms attract to open innovation platforms? The role of knowledge diversity and motivation. Long Range Planning, 44(5-6), 397-420. https://doi.org/10.1016/j.lrp.2011.09.006

Gassman, O., Enkel, E., \& Chesbrough, H. (2010). The future of open innovation. R\&D Management, 40(3), 213-221. https://doi.org/10.1111/j.1467-9310.2010.00605.x

Gaule, A. (2011). Common Mistakes and Stress Points. In: Sloane, P. (ed.), A Guide to Open Innovation and Crowd-sourcing. Expert Tips and Advice (pp. 170-177). London: Kogan Page Publisher.

Glase, B. G., \& Strauss, A. L. (1967). The discovery of grounded theory: Strategies for qualitative research. New York: Aldlne.

Hambrick, D. C., Finkelstein, S., \& Mooney, A. C. (2005). Executive job demands: New insights for explaining strategic decisions and leader behaviors. Academy of Management Review, 30(3), 472-491. https://doi.org/10.5465/amr.2005.17293355

Hegarty, W. H., \& Hoffman, R. C. (1990). Product/market innovations: a study of top management involvement among four cultures. Journal of Product Innovation Management, 7(3), 186-199. https://doi.org/10.1016/0737-6782(90)90003-W

Hopkins, R. (2011). What is crowd-sourcing?. In: Sloane, P. (ed.), A Guide to Open Innovation and Crowd-sourcing. Expert Tips and Advice (pp.15-21). London: Kogan Page Publisher.

Huber, G. P., \& Power, D. J. (1985). Retrospective Reports of Strategic-Level Managers: Guidelines for Increasing their Accuracy, Strategic Management Journal, 6(2), 171-180. https://doi.org/10.1002/smj.4250060206

Ili, S., Albers, A., \& Miller, S. (2010). Open innovation in the automotive industry. R\&D Management, 40(3), 246-255. https://doi.org/10.1111/j.1467-9310.2010.00595.x

Karlsson, C., \& Sköld, M. (2013). Forms of innovation openness in global automotive groups. International Journal of Automotive Technology and Management, 13(1), 1-17. https://doi.org/10.1504/IJATM.2013.052776

King, A., \& Lakhani, K. R. (2013). Using open innovation to identify the best ideas. MIT Sloan Management Review, 55(1), 41-48. 
KPMG (2015). KPMG's Global Automotive Executive Survey. Report retrieved from https://assets.kpmg.com

Laursen, K., \& Salter, A. (2006). Open for innovation: The role of openness in explaining innovation performance among U.K. manufacturing firms. Strategic Management Journal, 27, 131-150. https://doi.org/10.1002/smj.507

Lazzarotti, V., Manzini, R., Pellegrini, L., \& Pizzurno, E. (2013). Open Innovation in the automotive industry: Why and How? Evidence from a multiple case study. International Journal of Technology Intelligence and Planning, 9(1), 37-56. https://doi.org/10.1504/IJTIP.2013.052620

Logan, J. (2011). Tesla Motors Analysis. Retrieved 2013, May $1^{\text {st }}$, retrieved from www.johnloganfund.com/2011/05/tesla-motors.

Loren, J. K. (2011). What is Open Innovation?. In: Sloane, P. (ed.), A Guide to Open Innovation and Crowd-sourcing. Expert Tips and Advice (pp. 5-14). London: Kogan Page Publisher.

MacNeill, S., \& Bailey, D. (2010). Changing Policies for the Automotive Industry in an 'Old' Industrial Region: An Open Innovation Model for the UK West Midlands?. International Journal of Automotive Technology and Management, 10(2-3), 128-144. https://doi.org/10.1504/IJATM.2010.03262

Matricano, D. (2017). Open Innovation: a virtuous process of inbound and outbound knowledge flows. In W. D. Nelson (Ed.), Advances in Business Management, 14(4), 127-153. Nova Science Publisher.

Matricano, D. (2018). The state of the art of open innovation culture. In P. Formica, \& M. Curley (Eds.), Exploring the Culture of Open Innovation: Towards an Altruistic Model of Economy (chapter 5), Emerald Publishing Limited.

Miller, R. (1994). Global R\&D networks and large-scale innovations: The case of the automobile industry. Research Policy, 23(1), 27-46. https://doi.org/10.1016/0048-7333(94)90025-6

O'Cass, A., \& Sok, P. (2013). Exploring innovation driven value creation in B2B service firms: The roles of the manager, employees, and customers in value creation. Journal of Business Research, 66(8), 1074-1084. ttps://doi.org/10.1016/j.jbusres.2012.03.004

Peters, J., \& Becker, W. (1997). Vertical corporate networks in the German automotive industry: Structure, efficiency, and R\&D spillovers. International Studies of Management \& Organization, 27(4), 158-185. https://doi.org/10.1080/00208825.1997.11656722

Phillips, J. (2011) Open innovation typology. In: Sloane, P. (ed.), A Guide to Open Innovation and Crowd-sourcing. Expert Tips and Advice (pp. 22-36). London: Kogan Page Publisher.

Prensky, M. (2001). Digital natives, digital immigrants. On the Horizon, 9(5), 1-6.

Rayna, T., \& Striukova, L (2015). Open innovation 2.0: is co-creation the ultimate challenge?. International Journal of Technology Management, 69(1), 38-53. https://doi.org/10.1504/IJTM.2015.071030

Rosing, K., Frese, M., \& Bausch, A. (2011). Explaining the heterogeneity of the leadership-innovation relationship: Ambidextrous leadership. The Leadership Quarterly, 22(5), 956-974. https://doi.org/10.1016/j.leaqua.2011.07.014

Rubenstein, J. M. (2014). A Profile of the Automobile and Motor Vehicle Industry. New York: Business Expert Press.

Saldanha, F. P., Cohendet, P., \& Pozzebon, M. (2014). Challenging the Stage-Gate Model in Crowdsourcing: The Case of Fiat Mio in Brazil. Technology Innovation Management Review, 4, 28-35.

Sieg, J. H., Wallin, M. W., \& Von Krogh, G. (2010). Managerial challenges in open innovation: a study of innovation intermediation in the chemical industry. $R \& D$ Management, 40(3), 281-291. https://doi.org/10.1111/j.1467-9310.2010.00596.x

Smith, W. K., \& Tushman, M. L. (2005). Managing strategic contradictions: A top management model for $\begin{array}{llll}\text { managing innovation } & \text { streams. Organization } & \text { 522-536. }\end{array}$ https://doi.org/10.1287/orsc.1050.0134

Wang, X., \& Dass, M. (2017). Building innovation capability: The role of top management innovativeness and

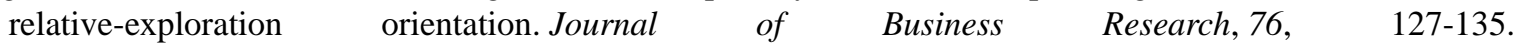
https://doi.org/10.1016/j.jbusres.2017.03.019

Whelan, E., Teigland, R., Donnellan, B., \& Golden, W. (2010) How internet technologies impact information flows in R\&D: reconsidering the technological gatekeeper. $R \& D$ Management, 40(4), 400-413. 
https://doi.org/10.1111/j.1467-9310.2010.00610.x

Wilhelm, M., \& Dolfsma, W. (2018). Managing knowledge boundaries for open innovation-lessons from the automotive industry. International Journal of Operations \& Production Management, 38(1), 230-248.

Wooten, J. O., \& Ulrich, K. T. (2017). Idea generation and the role of feedback: Evidence from field experiments with innovation tournaments. Production and Operations Management, 26(1), 80-99. https://doi.org/10.1111/poms.12613

Yin, R. K. (1994). Discovering the future of the case study method in evaluation research. Evaluation Practice, 15(3), 283-290. https://doi.org/10.1177/109821409401500309

Zogaj, S., Bretschneider, U., \& Leimeister, J. M. (2014). Managing crowdsourced software testing: a case study based insight on the challenges of a crowdsourcing intermediary. Journal of Business Economics, 84(3), 375-405. https://doi.org/10.1007/s11573-014-0721-9

\section{Copyrights}

Copyright for this article is retained by the author(s), with first publication rights granted to the journal.

This is an open-access article distributed under the terms and conditions of the Creative Commons Attribution license (http://creativecommons.org/licenses/by/4.0/). 